\title{
What Should Thoracic Surgeons Consider during Surgery for Ground-Glass Nodules?: Lymph Node Dissection
}

\author{
Hong Kwan Kim, M.D., Ph.D. \\ Department of Thoracic and Cardiovascular Surgery, Samsung Medical Center, Sungkyunkwan University School of Medicine, Seoul, Korea
}

\author{
ARTICLE INFO \\ Received April 16, 2021 \\ Revised August 11, 2021 \\ Accepted September 2, 2021 \\ Corresponding author \\ Hong Kwan Kim \\ Tel 82-2-3410-1687 \\ Fax 82-2-3410-6986 \\ E-mail hkts@skku.edu \\ ORCID \\ https://orcid.org/0000-0002-7815-3336
}

\begin{abstract}
Thoracic surgeons need to be aware of several important points regarding intraoperative lymph node dissection during surgery for non-small cell lung cancer with ground-glass opacities. The first point relates to the need for lymph node dissection during sublobar resection. Since even patients undergoing sublobar resection may benefit from lymph node dissection, it should be selectively performed according to adequate indications, which require further study. Second, there seems to be no difference in postoperative morbidity between systematic sampling and systematic dissection, but the survival benefit from systematic dissection remains unclear. The results of randomized controlled trials on this topic are conflicting, and their evidence is jeopardized by a high risk of bias in terms of the study design. Therefore, further randomized controlled trials with a sound design should investigate this issue. Third, more favorable survival outcomes tend to be positively associated with the number of examined lymph nodes. Minimum requirements for the number of examined lymph nodes in non-small cell lung cancer should be defined in the future. Finally, lobe-specific lymph node dissection does not have a negative prognostic impact. It should not be routinely performed, but it can be recommended in selected patients with smaller, less invasive tumors. Results from an ongoing randomized controlled trial on this topic should be awaited.
\end{abstract}

Keywords: Lung neoplasms, Ground-glass nodule, Lymph node excision, Surgery, N stage

\section{Introduction}

Approximately $20 \%$ of patients with non-small cell lung cancer (NSCLC) are diagnosed after the cancer has spread to the ipsilateral mediastinal lymph nodes (LNs; N2 metastasis), and due to the risk of occult microscopic systemic metastasis and resultant distant recurrence, their prognosis after surgery alone is poor [1]. Despite a thorough mediastinal staging workup to identify the presence of nodal involvement, the incidence of unforeseen N2 disease during surgery is reported to range from $4 \%$ to $18 \%$ [2-13]. Therefore, it is of considerable importance to predict N2 metastasis given its prognostic implications before deciding on a therapeutic strategy. Numerous researchers have investigated the predictors of occult N2 metastasis, including histologic type, tumor location, tumor size, size of consolidations or ground-glass opacities, and fluorodeoxyglucose uptake on positron emission tomography (Table 1) [2-15].
For instance, patients with features such as invasive adenocarcinoma, a centrally located tumor, tumor size greater than $2 \mathrm{~cm}$, a higher consolidation/tumor ratio $(\geq 0.5)$, or higher maximum standardized uptake values on positron emission tomography are more likely to have occult N2 metastasis. Therefore, performing a thorough staging workup for patients with these features is important. Conversely, patients who do not present with these features are typically candidates for sublobar resection. However, there is no consensus regarding the type of LN assessment that is appropriate in these patients undergoing sublobar resection. In other words, the question arises: is it truly necessary to perform complete LN dissection in patients who are less likely to have occult N2 disease? 
Table 1. Predictors of occult nodal metastasis

\begin{tabular}{|c|c|c|c|c|c|}
\hline Study & Year & $\begin{array}{c}\text { No. of } \\
\text { patients }\end{array}$ & Histologic type & Stage & Predictors of occult nodal metastasis \\
\hline Kanzaki et al. [6] & 2011 & 224 & NSCLC & $\mathrm{cN} 0-1$ & Adenocarcinoma, upper/middle lobe, size (3 cm), SUVmax (4) \\
\hline Gomez-Caro et al. [4] & 2012 & 153 & NSCLC & cT1-2N0 & Size $(5 \mathrm{~cm}), \mathrm{pN} 1$, adenocarcinoma, female \\
\hline Koike et al. [14] (2012) & 2012 & 894 & NSCLC & cStage IA & Age $(\leq 67 \mathrm{yr})$, size $(2 \mathrm{~cm}), \mathrm{CEA}(3.5 \mathrm{ng} / \mathrm{mL}), \mathrm{C} / \mathrm{T}$ ratio $(0.89)$ \\
\hline Li et al. [7] & 2013 & 189 & NSCLC & $\mathrm{cT} 1-2 \mathrm{~N} 0$ & Size $(3 \mathrm{~cm})$, SUVmax $(4.3)$ \\
\hline Miyasaka et al. [9] & 2013 & 265 & NSCLC & cNO & $\mathrm{C} / \mathrm{T}$ ratio $(0.5), \mathrm{SUVmax}(10)$ \\
\hline Cho et al. [3] & 2013 & 770 & NSCLC & cStage I & Solid nodule, clinical T stage, CEA, GGO \\
\hline Ye et al. [12] & 2014 & 651 & Adenocarcinoma & cStage IA & Part-solid nodule, CEA (5 ng/mL), SUVmax (5), histologic subtype \\
\hline Wang et al. [11] & 2015 & 292 & NSCLC & cStage IA & Size $(2 \mathrm{~cm}), \mathrm{C} / \mathrm{T}$ ratio $(0.5)$, micropapillary pattern \\
\hline Haruki et al. [15] (2015) & 2015 & 876 & NSCLC & cStage I & $\mathrm{C} / \mathrm{T}$ ratio $(0.5), \mathrm{CEA}(5 \mathrm{ng} / \mathrm{mL})$ \\
\hline Lin et al. [8] & 2016 & 284 & NSCLC & cNo & SUVmax (2.6) \\
\hline Moon et al. [10] & 2016 & 350 & Adenocarcinoma & $\mathrm{cNO}$ & SUVmax (5), lymphovascular invasion, micropapillary pattern \\
\hline Hung et al. [5] & 2016 & 471 & Adenocarcinoma & $\mathrm{cNO}(<3 \mathrm{~cm})$ & Size, micropapillary/solid pattern \\
\hline Yeh et al. [13] & 2016 & 297 & Adenocarcinoma & $\mathrm{cN} 0-1$ & Micropapillary pattern \\
\hline Bille et al. [2] & 2017 & 1,667 & NSCLC & cStage I & Adenocarcinoma, vascular invasion \\
\hline
\end{tabular}

NSCLC, non-small cell lung cancer; SUVmax, maximum standardized uptake value; CEA, carcinoembryonic antigen; C/T ratio, consolidation/ tumor ratio; GGO, ground-glass opacity.

\section{Intraoperative nodal assessment during sublobar resection}

For non-invasive or minimally invasive lung tumors such as adenocarcinoma in situ or minimally invasive adenocarcinoma, it is reasonable to perform sublobar resection while omitting LN dissection. Likewise, for invasive adenocarcinomas larger than $2 \mathrm{~cm}$, lobectomy and complete LN dissection should be conducted. However, for tumors with borderline features, the optimal extent of pulmonary resection and whether to perform complete nodal dissection remain a topic of debate. Cao et al. [16] investigated the prognostic impact of lymphadenectomy in patients undergoing sublobar resection for stage IA NSCLC tumors smaller than $2 \mathrm{~cm}$ using data from the Surveillance, Epidemiology, and End Results (SEER) database. They demonstrated that more extensive regional LN dissection ( $\geq 4$ regional LNs) was associated with better lung cancer-specific survival rates than less extensive regional LN dissection (1-3 regional LNs). Their findings suggest that adequate $\mathrm{LN}$ assessment is required even in patients undergoing sublobar resection for stage IA NSCLC. Similarly, Stiles et al. [17] compared the oncologic effectiveness between lobectomy and sublobar resection according to the extent of LN dissection in patients with stage I NSCLC smaller than $2 \mathrm{~cm}$ from the SEER database. When propensity-matched cohorts of patients with at least $1 \mathrm{LN}$ removed were examined, the survival rate of sublobar resection was worse than that of lobectomy. However, when cohorts were propensity-matched for having had $\geq 9$ LNs examined, the difference in overall survival or cancer-specific survival disappeared. These findings imply that the oncological outcomes of sublobar resection can be equivalent to those of lobectomy as long as an adequate LN assessment is performed.

\section{Adequate extent of nodal assessment: sampling versus dissection}

Regarding the adequate extent of LN assessment, whether systematic LN sampling is sufficient or the lymphatic tissue and surrounding fatty tissue within the LN station should be completely removed along its anatomical boundaries is also a matter of debate. Compared with systematic sampling, the accuracy of staging can be enhanced after complete lymphadenectomy, resulting in increased detection of occult N2 disease. However, complete lymphadenectomy could lead to increased postoperative morbidity such as chylothorax or recurrent laryngeal nerve injury. Nevertheless, whether complete lymphadenectomy can translate into therapeutic effectiveness and a resulting survival benefit remains unclear. Five randomized controlled trials (RCTs) have been published on this topic (Table 2) [18-22]. Except for an American multi-institutional trial [18], all the studies were single-institutional trials. While patients with stage III disease were included in a German trial [19] and Chinese trials [21,22], the Japanese and American trials $[18,20]$ only enrolled patients with stage I or II disease. Except for the American trial, which enrolled about 1,100 patients, most studies were limited to a small 
Table 2. Summary of randomized controlled trials on the extent of optimal nodal assessment

\begin{tabular}{|c|c|c|c|c|c|c|c|c|c|}
\hline Study & Year & Country & $\begin{array}{c}\text { No. of } \\
\text { participating } \\
\text { centers }\end{array}$ & Stage & No. of patients & Morbidity & $\begin{array}{l}\text { Staging } \\
\text { accuracy }\end{array}$ & $\begin{array}{c}\text { Survival } \\
\text { outcomes }\end{array}$ & Critical points \\
\hline $\begin{array}{l}\text { Izbicki } \\
\text { et al. [19] }\end{array}$ & 1994 & Germany & Single & I-IIIA & $\begin{array}{l}\text { Dissection } \\
\quad(n=76) \\
\text { Sampling }(n=93)\end{array}$ & $\mathrm{D} \approx \mathrm{S}$ & $\mathrm{D}>\mathrm{S}$ & $\mathrm{D} \approx \mathrm{S}$ & $\begin{array}{l}\text { - Small sample size } \\
\text { - More SqCC in the } \\
\text { dissection group }\end{array}$ \\
\hline $\begin{array}{l}\text { Sugi et al. } \\
\text { [20] }\end{array}$ & 1998 & Japan & Single & $\begin{array}{l}\text { Peripheral } \\
<2 \mathrm{~cm}\end{array}$ & $\begin{array}{l}\text { Dissection } \\
\quad(n=59) \\
\text { Sampling }(n=56)\end{array}$ & $\mathrm{D}>\mathrm{S}$ & $\mathrm{D} \approx \mathrm{S}$ & $\mathrm{D} \approx \mathrm{S}$ & $\begin{array}{l}\text { - Small sample size } \\
\text { - Short follow-up } \\
\text { duration }\end{array}$ \\
\hline $\begin{array}{l}\text { Wu et al. } \\
\text { [21] }\end{array}$ & 2002 & China & Single & I-IIIA & $\begin{array}{l}\text { Dissection } \\
\quad(n=240) \\
\text { Sampling }(n=231)\end{array}$ & $\mathrm{D} \approx \mathrm{S}$ & NR & $\mathrm{D}>\mathrm{S}$ & $\begin{array}{l}\text { - Small sample size } \\
\text { - More stage IIIA in } \\
\text { the dissection group }\end{array}$ \\
\hline $\begin{array}{l}\text { Darling } \\
\text { et al. [18] }\end{array}$ & 2011 & USA & $\begin{array}{l}\text { Multiple } \\
\text { (ACOSOG) }\end{array}$ & N0-N1 & $\begin{array}{l}\text { Dissection } \\
\quad(n=525) \\
\text { Sampling }(n=498)\end{array}$ & $\mathrm{D} \approx \mathrm{S}$ & $\mathrm{D}>\mathrm{S}$ & $\mathrm{D} \approx \mathrm{S}$ & $\begin{array}{l}\text { - Rigorous } \\
\text { sampling before } \\
\text { randomization }\end{array}$ \\
\hline $\begin{array}{l}\text { Zhang } \\
\text { et al. [22] }\end{array}$ & 2013 & China & Single & I-IIIA & $\begin{array}{l}\text { Minimal LND } \\
(\mathrm{n}=107) \\
\text { Complete LND } \\
(\mathrm{n}=95)\end{array}$ & $\mathrm{D} \approx \mathrm{S}$ & $\mathrm{D} \approx \mathrm{S}$ & $\mathrm{D}>\mathrm{S}$ & - Small sample size \\
\hline
\end{tabular}

D, dissection; S, sampling; $\approx$, 2 groups are similar; SqCC, squamous cell carcinoma; ACOSOG, the American College of Surgeons Oncology Group Z0030 trial; NR, not reported; LND, lymph node dissection.

sample. There were no significant differences in the incidence of postoperative morbidities between sampling and dissection. The German and American trials reported that dissection was better than sampling in terms of detection of occult N2 disease $[18,19]$, whereas the remaining trials found no difference between groups. Importantly, while 2 Chinese trials observed better survival after dissection than after sampling $[21,22]$, the other trials reported no difference in survival outcomes between groups.

Despite the clinical implications of these trials, many critical limitations are still present. In the trial by $\mathrm{Wu}$ et al. [21], more patients with stage IIIA disease were included in the dissection group than in the sampling group. The American trial was criticized for its study design, in which the difference between groups was intrinsically impossible to detect since all the patients had already undergone extensive sampling before randomization [18]. Moreover, there were serious uncertainties and risks of bias in the methods of all the studies, including the lack of an intention-to-treat analysis (5 trials) [18-22], unclear random sequence generation (4 trials) [18,20-22] or allocation concealment (5 trials) [18-22], and impossible blinding (5 trials) [18-22]. To overcome the limitations of each trial, some researchers have conducted meta-analyses (Table 3) [23-25]. So far, 3 meta-analyses have been published. Among them, the first study by Wright et al. [25] analyzed 3 RCTs, showing that dissection was associated with better survival than sampling. As the American trial that did not find a difference in survival between groups was included in the second meta-analysis by Huang et al. [23], the difference in survival outcomes subsequently disappeared. In contrast, the third meta-analysis by Mokhles et al. [24] demonstrated a survival difference between groups again because it included the Chinese RCT by Zhang et al. [22] that showed a difference in survival outcomes. Mokhles et al. [24] indicated that the claimed survival benefit from mediastinal LN dissection is not supported by reliable evidence, and they emphasized that the overall value of $\mathrm{LN}$ dissection should ideally be tested in a large pragmatic RCT involving contemporary diagnostic, surgical, and oncological practice.

\section{Issues regarding the prognostic implications of the number of examined lymph nodes}

The absolute number of LNs removed is a surrogate marker of the quality and extent of LN assessment. However, there is no strict guideline on the number of harvested LNs in lung cancer treatment, whereas the minimum requirements for the number of LNs to assess have already been published for various kinds of solid malignancies other than lung cancer. Some investigators have recently attempted to determine the minimal threshold for the examined LN count by correlating the number of examined LNs with long-term survival in NSCLC [26-30]. Of note, 
Table 3. Summary of meta-analyses of RCTs on the extent of optimal nodal assessment

\begin{tabular}{|c|c|c|c|c|c|}
\hline Study & RCTs & Morbidity & Survival & Local recurrence & Distant metastasis \\
\hline Wright et al. [25] & $\begin{array}{l}\text { Izbicki et al. [19] (1994) } \\
\text { Sugi et al. [20] (1998) } \\
\text { Wu et al. [21] (2002) }\end{array}$ & $\mathrm{D} \approx \mathrm{S}$ & $\mathrm{D}>\mathrm{S}$ & NR & NR \\
\hline Huang et al. [23] & $\begin{array}{l}\text { lzbicki et al. [19] (1994) } \\
\text { Sugi et al. [20] (1998) } \\
\text { Wu et al. [21] (2002) } \\
\text { Darling et al. [18] (2011) }\end{array}$ & $\mathrm{D} \approx \mathrm{S}$ & $\mathrm{D} \approx \mathrm{S}$ & $\mathrm{D} \approx \mathrm{S}$ & $\mathrm{D} \approx \mathrm{S}$ \\
\hline Mokhles et al. [24] & $\begin{array}{l}\text { lzbicki et al. [19] (1994) } \\
\text { Sugi et al. [20] (1998) } \\
\text { Wu et al. [21] (2002) } \\
\text { Darling et al. [18] (2011) } \\
\text { Zhang et al. [22] (2013) }\end{array}$ & $\mathrm{D} \approx \mathrm{S}$ & $\mathrm{D}>\mathrm{S}$ & $\mathrm{D} \approx \mathrm{S}$ & $\mathrm{D} \approx \mathrm{S}$ \\
\hline
\end{tabular}

RCT, randomized controlled trial; $\mathrm{D}$, dissection; $\mathrm{S}$, sampling; $\approx 2$ groups are similar; NR, not reported.

Liang et al. [27] found that a greater number of examined LNs was associated with more accurate nodal staging and better long-term survival of resected NSCLC. Therefore, they recommended 16 examined LNs as the cut-off for evaluating the quality of LN examinations. Some researchers have argued that the ratio of metastatic LNs to total examined LNs is a better predictor of survival after surgery for NSCLC [26,28-30]. Nwogu et al. [28] explored the prognostic implication of the LN ratio by stratifying the percentage of positive LNs into 3 groups $(1 \%-24 \%$ versus $25 \%-49 \%$ versus $50 \%-100 \%$ ) in NSCLC patients who underwent curative resection and had at least $1 \mathrm{LN}$ examined from the SEER database. They found that more LNs resected and lower ratios of positive LNs to total examined LNs were associated with better survival. However, we should be cautious in interpreting the results of the numerous reports that showed the prognostic value of LN number or $\mathrm{LN}$ ratio. First, the number of examined LNs can be overestimated since grasping LNs with more force and traction during surgery could result in fragmentation of LNs due to accidental cutting and crushing. Second, there are no standardized criteria for LN counting during the pathological examination. Third, the cut-off points of the adequate LN number or ratio are too arbitrary.

\section{Lobe-specific lymph node dissection}

It is well known that the lymphatic drainage pattern differs among the lobes of the lung. Tumors in the upper lobe are more likely to metastasize to the upper mediastinal LNs, whereas tumors in the lower lobe are more likely to metastasize to the lower mediastinal LNs [31]. If the primary tumor is located in the upper lobe, only the LNs in the upper mediastinum are removed, and the lower mediasti- nal LNs are left undissected and vice versa. This could result in adequate LN assessment without unnecessary dissection of the LNs where tumors are unlikely to metastasize. Okada et al. [31] emphasized that lower mediastinal LN dissection is not needed if the hilar and upper mediastinal LNs are found to be free and vice versa based on the lobe-specific lymphatic drainage pattern. Recently, Adachi et al. [32] compared the oncological efficacy between lobe-specific LN dissection (LS-LND) and systematic LN dissection (S-LND) in a multi-institutional database of surgery for NSCLC using a propensity score-matching method. They demonstrated that the survival rates and pathologic N2 detection rates of LS-LND were not inferior to those of S-LND. Similarly, Hishida et al. [33] assessed the surgical outcomes of 5,392 patients with clinical stage I or II NSCLC according to the extent of mediastinal LN dissection using a nationwide registry database. Although there was no significant difference in the incidence of postoperative complications between LS-LND and S-LND, the survival outcomes of the former were better than that of the latter. This might be due to the fact that the LS-LND group had smaller tumors at an earlier stage than the S-LND group.

Despite the promising results of LS-LND, the data must be interpreted carefully. First, higher mediastinal LN recurrence has been reported after LS-LND in some studies. Second, most studies showed that LS-LND did not substantially decrease postoperative morbidities despite the compromise in LN assessment. Third, the favorable outcomes of LS-LND might be due to selection bias, given that LS-LND is more likely to be conducted for pathologically less invasive tumors. In some studies, LS-LND was converted to S-LND during surgery upon suspicion of LN metastasis. More importantly, there have been no RCTs on 
this topic. Above all, the opponents of LS-LND insist that not all tumors follow lobe-specific lymphatic drainage patterns. For example, Chinese researchers reported that different primary tumor locations had different propensities to be sites of mediastinal LN metastases [34]. However, once mediastinal LN metastasis occurs, each zone has the potential to be involved and should not be neglected based on the lobe-specific lymphatic drainage pattern. Therefore, we need to specify the indication of LS-LND based on further studies and select LS-LND in the borderline zone between patients who do not need LN dissection and those who must receive complete $\mathrm{LN}$ dissection. A randomized phase 3 trial of lobe-specific versus systematic LN dissection for clinical stage I or II NSCLC (Japan Clinical Oncology Group [JCOG] 1413) is currently underway [35], and we need to await the results of this trial before reaching a conclusion on this topic.

\section{Conclusion}

In summary, thoracic surgeons need to be aware of several important points about intraoperative $\mathrm{LN}$ dissection during surgery for NSCLC with ground-glass opacities. The first point relates to the need for $\mathrm{LN}$ dissection during sublobar resection. Since even patients undergoing sublobar resection may benefit from LN dissection, it should be selectively performed according to adequate indications, which require further study. Second, there seems to be no difference in postoperative morbidity between systematic sampling and systematic dissection, but the survival benefit from systematic dissection remains unclear. The results of RCTs on this topic are conflicting, and their evidence is jeopardized by a high risk of bias in terms of the study design. Therefore, further well-designed RCTs must be done to clarify this point. Third, there is a tendency for more favorable survival as more LNs are examined. Minimum requirements for the number of examined LNs in NSCLC should be defined in the future. Finally, LS-LND does not have a negative prognostic impact. LS-LND should not be routinely performed, but it can be recommended in selected patients with small, less invasive tumors. Results from the ongoing RCT on this topic should be awaited.

\section{Conflict of interest}

No potential conflict of interest relevant to this article was reported.

\section{ORCID}

Hong Kwan Kim: https://orcid.org/0000-0002-7815-3336

\section{References}

1. Siegel RL, Miller KD, Jemal A. Cancer statistics, 2020. CA Cancer J Clin 2020;70:7-30

2. Bille A, Woo KM, Ahmad U, Rizk NP, Jones DR. Incidence of occult pN2 disease following resection and mediastinal lymph node dissection in clinical stage I lung cancer patients. Eur J Cardiothorac Surg 2017;51:674-9.

3. Cho S, Song IH, Yang HC, Kim K, Jheon S. Predictive factors for node metastasis in patients with clinical stage I non-small cell lung cancer. Ann Thorac Surg 2013;96:239-45

4. Gomez-Caro A, Boada M, Cabanas M, et al. False-negative rate after positron emission tomography/computer tomography scan for mediastinal staging in cI stage non-small-cell lung cancer. Eur J Cardiothorac Surg 2012;42:93-100.

5. Hung JJ, Yeh YC, Jeng WJ, Wu YC, Chou TY, Hsu WH. Factors predicting occult lymph node metastasis in completely resected lung adenocarcinoma of $3 \mathrm{~cm}$ or smaller. Eur J Cardiothorac Surg 2016;50: 329-36.

6. Kanzaki R, Higashiyama M, Fujiwara A, et al. Occult mediastinal lymph node metastasis in NSCLC patients diagnosed as clinical N0-1 by preoperative integrated FDG-PET/CT and CT: risk factors, pattern, and histopathological study. Lung Cancer 2011;71:333-7.

7. Li L, Ren S, Zhang Y, et al. Risk factors for predicting the occult nodal metastasis in T1-2NOMO NSCLC patients staged by PET/CT: potential value in the clinic. Lung Cancer 2013;81:213-7.

8. Lin JT, Yang XN, Zhong WZ, et al. Association of maximum standardized uptake value with occult mediastinal lymph node metastases in cN0 non-small cell lung cancer. Eur J Cardiothorac Surg 2016; 50:914-9.

9. Miyasaka Y, Suzuki K, Takamochi K, Matsunaga T, Oh S. The maximum standardized uptake value of fluorodeoxyglucose positron emission tomography of the primary tumour is a good predictor of pathological nodal involvement in clinical NO non-small-cell lung cancer. Eur J Cardiothorac Surg 2013;44:83-7.

10. Moon Y, Kim KS, Lee KY, Sung SW, Kim YK, Park JK. Clinicopathologic factors associated with occult lymph node metastasis in patients with clinically diagnosed NO lung adenocarcinoma. Ann Thorac Surg 2016;101:1928-35.

11. Wang L, Jiang W, Zhan C, et al. Lymph node metastasis in clinical stage IA peripheral lung cancer. Lung Cancer 2015;90:41-6.

12. Ye B, Cheng M, Li W, et al. Predictive factors for lymph node metastasis in clinical stage IA lung adenocarcinoma. Ann Thorac Surg 2014;98:217-23.

13. Yeh YC, Kadota K, Nitadori J, et al. International Association for the 
Study of Lung Cancer/American Thoracic Society/European Respiratory Society classification predicts occult lymph node metastasis in clinically mediastinal node-negative lung adenocarcinoma. Eur J Cardiothorac Surg 2016;49:e9-15.

14. Koike T, Koike T, Yamato Y, Yoshiya K, Toyabe S. Predictive risk factors for mediastinal lymph node metastasis in clinical stage IA non-small-cell lung cancer patients. J Thorac Oncol 2012;7:1246-51.

15. Haruki T, Aokage K, Miyoshi T, et al. Mediastinal nodal involvement in patients with clinical stage I non-small-cell lung cancer: possibility of rational lymph node dissection. J Thorac Oncol 2015;10:930-6.

16. Cao J, Xu J, He Z, et al. Prognostic impact of lymphadenectomy on outcomes of sublobar resection for stage IA non-small cell lung cancer $\leq 2 \mathrm{~cm}$. J Thorac Cardiovasc Surg 2018;156:796-805.

17. Stiles BM, Mao J, Harrison S, et al. Extent of lymphadenectomy is associated with oncological efficacy of sublobar resection for lung cancer $\leq 2 \mathrm{~cm}$. J Thorac Cardiovasc Surg 2019;157:2454-65.

18. Darling GE, Allen MS, Decker PA, et al. Randomized trial of mediastinal lymph node sampling versus complete lymphadenectomy during pulmonary resection in the patient with NO or N1 (less than hilar) non-small cell carcinoma: results of the American College of Surgery Oncology Group Z0030 Trial. J Thorac Cardiovasc Surg 2011;141:662-70.

19. Izbicki JR, Thetter O, Habekost M, et al. Radical systematic mediastinal lymphadenectomy in non-small cell lung cancer: a randomized controlled trial. Br J Surg 1994;81:229-35.

20. Sugi K, Nawata K, Fujita N, et al. Systematic lymph node dissection for clinically diagnosed peripheral non-small-cell lung cancer less than $2 \mathrm{~cm}$ in diameter. World J Surg 1998;22:290-4.

21. Wu Yl, Huang ZF, Wang SY, Yang XN, Ou W. A randomized trial of systematic nodal dissection in resectable non-small cell lung cancer. Lung Cancer 2002;36:1-6.

22. Zhang J, Mao T, Gu Z, Guo X, Chen W, Fang W. Comparison of complete and minimal mediastinal lymph node dissection for nonsmall cell lung cancer: results of a prospective randomized trial. Thorac Cancer 2013;4:416-21.

23. Huang X, Wang J, Chen Q, Jiang J. Mediastinal lymph node dissection versus mediastinal lymph node sampling for early stage nonsmall cell lung cancer: a systematic review and meta-analysis. PLoS One 2014;9:e109979.

24. Mokhles S, Macbeth F, Treasure T, et al. Systematic lymphadenectomy versus sampling of ipsilateral mediastinal lymph-nodes during lobectomy for non-small-cell lung cancer: a systematic review of randomized trials and a meta-analysis. Eur J Cardiothorac Surg 2017; 51:1149-56.

25. Wright G, Manser RL, Byrnes G, Hart D, Campbell DA. Surgery for non-small cell lung cancer: systematic review and meta-analysis of randomised controlled trials. Thorax 2006;61:597-603.

26. Ding N, Pang Z, Zhang X, et al. Prognostic and predictive effects of positive lymph node number or ratio in NSCLC. Sci Rep 2017;7:584.

27. Liang W, He J, Shen Y, et al. Impact of examined lymph node count on precise staging and long-term survival of resected non-small-cell lung cancer: a population study of the US SEER Database and a Chinese multi-institutional registry. J Clin Oncol 2017;35:1162-70.

28. Nwogu CE, Groman A, Fahey D, et al. Number of lymph nodes and metastatic lymph node ratio are associated with survival in lung cancer. Ann Thorac Surg 2012;93:1614-9.

29. Qiu C, Dong W, Su B, Liu Q, Du J. The prognostic value of ratio-based lymph node staging in resected non-small-cell lung cancer. J Thorac Oncol 2013;8:429-35.

30. Wang CL, Li Y, Yue DS, Zhang LM, Zhang ZF, Sun BS. Value of the metastatic lymph node ratio for predicting the prognosis of nonsmall-cell lung cancer patients. World J Surg 2012;36:455-62.

31. Okada M, Sakamoto T, Yuki T, Mimura T, Miyoshi K, Tsubota N. Selective mediastinal lymphadenectomy for clinico-surgical stage I non-small cell lung cancer. Ann Thorac Surg 2006;81:1028-32.

32. Adachi H, Sakamaki K, Nishii T, et al. Lobe-specific lymph node dissection as a standard procedure in surgery for non-small cell lung cancer: a propensity score matching study. J Thorac Oncol 2017;12: 85-93.

33. Hishida T, Miyaoka E, Yokoi K, et al. Lobe-specific nodal dissection for clinical stage I and II NSCLC: Japanese multi-institutional retrospective study using a propensity score analysis. J Thorac Oncol 2016;11:1529-37.

34. Liang RB, Yang J, Zeng TS, et al. Incidence and distribution of lobe-specific mediastinal lymph node metastasis in non-small cell lung cancer: data from 4511 resected cases. Ann Surg Oncol 2018; 25:3300-7.

35. Hishida T, Saji H, Watanabe SI, et al. A randomized phase III trial of lobe-specific vs. systematic nodal dissection for clinical stage I-II non-small cell lung cancer (JCOG1413). Jpn J Clin Oncol 2018;48: 190-4. 